\title{
LA OMISIÓN LEGISLATIVA Y JUDICIAL DE LOS DERECHOS LINGÜIÍSTICOS DE LOS PUEBLOS INDÍGENAS EN VENEZUELA Y ECUADOR
}

\section{THE LEGISLATIVE AND JUDICIAL OMISSION OF LINGUISTIC RIGHTS OF INDIGENOUS PEOPLES IN VENEZUELA AND ECUADOR}

\author{
OMISION LEGISLATIVA Y JUDICIAL DE LOS DERECHOS \\ LINGÜISTICOS NISQATA KAY ÑAWPAQ AYLLUKUNAMANTA \\ VENEZUELA ECUADOR SUYUKUNAMANTA ${ }^{(1)}$
}

\author{
Pablo Ricardo Mendoza Escalante ${ }^{(2)}$ \\ Andrea Carolina Subía Cabrera ${ }^{2}$ \\ Elizabeth Ximena Maldonado Erazo ${ }^{3}$ \\ Universidad de Otavalo, Ecuador.
}

\begin{abstract}
Resumen: Este trabajo analiza el marco jurídico de los derechos culturales al uso de lenguas ancestrales en Ecuador y Venezuela. Mediante la investigación bibliográfica expone las normas vigentes sobre derechos lingüísticos indígenas frente a su posible vulneración. Comprueba que, en distintos ámbitos de la justicia, no se comprende la estructura y cosmovisión de las lenguas originarias. Propone la formulación de nuevas políticas públicas en los sistemas de justicia, bajo la óptica intercultural como eje central. Presenta la propuesta intercultural del Observatorio Jurídico de la Universidad de Otavalo.
\end{abstract}

Palabras Clave: Derechos lingüísticos, pueblos indígenas, omisión legislativajudicial, vulneración de derechos, interculturalidad, Otavalo

Abstract: This work analyzes the legal framework of cultural rights to the use of ancestral languages in Ecuador and Venezuela. Through bibliographic research,

(1) Traducción: Alejandra C. Ninahuaman Quispe, Kilmer Ttito Quispe (Lengua Quechua / Cusco Collao)

(2) Msc. Desarrollo Agrario de la Universidad de Los Andes-Venezuela y Docente de la Universidad de Otavalo-Ecuador. Email: pmendoza@uotavalo.edu.ec.

(2) Msc. Relaciones Internacionales y Diplomacia. Doctorante de Derecho. Docente investigador de La Universidad de Otavalo. Email: asubia@uotavalo.edu.ec.

(3) Msc. Derecho Constitucional. Docente investigador de La Universidad de Otavalo. Email:xmaldonado@uotavalo.edu.ec. 
it exposes the current norms on indigenous linguistic rights in the face of their possible violation. It verifies that, in different areas of justice, the structure and worldview of the original languages is not understood. It proposes the formulation of new public policies in justice systems, from an intercultural perspective as the central axis. Presents the intercultural proposal of the Legal Observatory of the University of Otavalo.

Keywords: Linguistic rights, indigenous peoples, legislative-judicial omission, interculturality, Otavalo.

Ñujñu: Kay qelqay qawarin marco jurídico de los derechos culturales nisqata kay ñawpaq rimakuykunata Ecuador Venezuela suyupi. Investigación bibliográfica chawpinmanta reqsichin kay normakunata kunankama kderechos nisqata ñawpaq ayllukuna rimayninkunata,

Reqsichin imaynata mana yachakunchu kay ñawpaq rimakuykuna qawarin, yuyarin teqsimuyunchista. Rimarin musuq políticas publicas nisqata chay sistema judicialpi, allin kawsari kanampaq llapan ayllukunawan. Qawarichin hoq ruasqankuta chay rimariykunata allin kawsari kanampaq Observatorio Jurídico nisqamanta chay Hatun Yachay wasi Otavalomanta.

Kichana rimaykuna: Derechos lingüísticos, ñawpa ayllukuna, omisión legislativa judicial nisqa, mana rispitichanki derechunkunata, allin kawsay llapan ayllukunawan, Otavalo. 


\section{Introducción}

La actualidad constitucional de Venezuela (1999) y de Ecuador (2008) sustenta el reconocimiento del carácter pluricultural en ambos Estados. Estas Constituciones establecen una nueva ruta epistemológica latinoamericana de respeto a la diversidad cultural y lingüística de sus pueblos originarios. En este contexto latinoamericano, como Estados constitucionales de derecho se consideran respetuosos del principio de igualdad formal y material, con garantía de que ninguna persona sea objeto de discriminación en razón de su origen, lengua, nacionalidad, ni de ninguna otra clase; con atención especial en la inclusión social de grupos y pueblos, es así que, como derecho colectivo, asegura a pueblos y nacionalidades conservar y valorar sus usos y costumbres, como el uso y difusión de sus idiomas ancestrales.

Este trabajo tiene como objetivo analizar el desarrollo de la categoría de derechos lingüísticos y describir el marco legal venezolano y ecuatoriano, para su exigibilidad. Esta investigación parte de la siguiente interrogante: ¿La omisión de los derechos lingüísticos de los pueblos indígenas en los ordenamientos jurídicos en Venezuela y Ecuador puede ser considerada una vulneración a sus derechos? En la presente investigación, el tipo de investigación utilizada fue la documental, la que se basó en legislación y doctrina para investigar el desarrollo de la categoría de derechos lingüísticos y describir el marco legal venezolano y ecuatoriano para su exigibilidad. Se empleó el método analítico y el método comparativo que detalla Nuria González citando a Capelleti, (2010, p. 21) aplicado al sistema jurídico ecuatoriano y al sistema jurídico venezolano. La técnica de investigación utilizada fue la recopilación bibliográfica.

Uno de los problemas que se visibiliza en el análisis del uso y difusión de signos, lenguas ancestrales y sus ramificaciones, se vincula a la ausencia de programas, políticas, normativas y principios del derecho que velen por la difusión, uso y protección de los dialectos propios de cada pueblo y nacionalidad, especialmente de poblaciones de etnia indígena. Este conocimiento ancestral necesita la revalorización en el proyecto de la diversidad que los Estados latinoamericanos integran. El uso oficial y su valoración en el ámbito público dentro de la nueva epistemología del sur se vincula a la interrelación mediante el diálogo y conocimiento diverso de los unos y los otros, en todos los ámbitos de la vida, es decir, el enfoque de interculturalidad, lo que permite introducir la necesidad de la práctica de costumbres ancestrales. Una de estas es el habla de las lenguas, los signos lingüísticos y sus ramificaciones.

Encuanto al reconocimiento expreso de losidiomas ancestrales, exceptuando el Kichwa y el Shuar, que están expresamente reconocidos en la Constitución ecuatoriana de 2008, la informalidad ha sido la condición en la que se han mantenido hasta la fecha el resto de las lenguas ancestrales en Venezuela y Ecuador. 
En relación al aprendizaje inicial de las personas, éste se logra a través del lenguaje por medio de la palabra que se transmite y desarrolla en el hogar, a medida que las personas se comunican se van creando nuevas formas de relación con la familia y la comunidad. Sociológicamente, las tradiciones lingüísticas se trasmiten por generaciones mediante el idioma, la pérdida del idioma es la pérdida de la cultura de una nación.

Cuando se aborda el tema de la diversidad lingüística de la humanidad es importante considerar que siempre existieron lenguas dominantes que marcaron las relaciones de poder en las esferas económicas, políticas y sobre todo jurídicas de esas sociedades, siendo esto aplicable a los pueblos indígenas como grupos tradicionalmente excluidos en la historia.

En este sentido, como lo expresa Yuri Oliveros Marín (2017. p.8): "en esa interacción de sociedades, las lenguas desfavorecidas han sido marginadas, silenciadas o han ido desapareciendo". Lo que aclara en parte las razones que han influido para que hayan desaparecido múltiples lenguas ancestrales en Latinoamérica, específicamente en Venezuela y Ecuador, destacándose la opresión y la exclusión social.

En este contexto introductorio, vale la pena considerar lo afirmado por Javier García León y David García León (2012. p. 2) "La coexistencia de lenguas en un mismo territorio es en ocasiones conflictiva. Muchas veces el Estado se ve obligado a regular dicha relación implantando políticas lingüisticas". Es así como se plantea la necesaria intervención estatal en la búsqueda de la armonía cuando en su territorio se evidencia la plurinacionalidad, tal es el caso de los Estados venezolano y ecuatoriano, donde es evidente la coexistencia de múltiples lenguas indígenas.

Desde el ámbito internacional el Convenio 169 de la Organización Internacional del Trabajo sobre Pueblos Indígenas y Tribales (1989), sustentado en el principio de autodeterminación, establece lo siguiente: "Los gobiernos deberán asumir la responsabilidad de desarrollar, con la participación de los pueblos interesados, una acción coordinada y sistemática con miras a proteger los derechos de esos pueblos y a garantizar el respeto de su integridad" (Art.2).

El propósito de este dispositivo se centra en los derechos en general de los pueblos indígenas y la obligación del principio de responsabilidad de los gobiernos de generar acciones de protección de estos. En este convenio también se establece que: "Al aplicar la legislación nacional a los pueblos interesados deberán tomarse debidamente en consideración sus costumbres o su derecho consuetudinario" (Art.8), lo que supone, dentro del actuar indígena en los ámbitos jurídicos en Venezuela y Ecuador, considerar la interculturalidad al momento que la administración pública o el sistema de justicia aplique el ordenamiento jurídico.

Otra de las normas que se relacionan con esta investigación es que el Convenio 169 de la OIT establece que: "Deberán tomarsemedidas para garantizarquelosmiembros 
de dichos pueblos puedan comprender y hacerse comprender en procedimientos legales, facilitándoles, si fuere necesario, intérpretes u otros medios eficaces" (Art.12).

De allí se deduce que los derechos lingüísticos de los pueblos indígenas solo serán efectivos si los Estados establecen medidas y normas internas en sus procesos judiciales que permitan la comunicación comprensiva cuando uno de los intervinientes sea un indígena, como es el caso de un intérprete. También contempla que: "Deberán adoptarse disposiciones para preservar las lenguas indígenas de los pueblos interesados y promover el desarrollo y la práctica de las mismas", en este particular insta a los Estados a generar política pública en la materia. "A tal fin, deberá recurrirse, si fuere necesario, a traducciones escritas y a la utilización de los medios de comunicación de masas en las lenguas de dichos pueblos"(Art.30). Por supuesto, el acceso al material escolar, jurídico, formativo en sus lenguas permitirá un verdadero acceso a la información nacional dentro de un contexto armónico en su alcance.

Posteriormente, respecto al Convenio Marco para la Protección de las Minorías Nacionales (1994), Juan Manuel Bautista (1995) hace la siguiente mención:

"El convenio marco para la protección de las minorías nacionales (...) representa un notable esfuerzo de juridificación de compromisos políticos destinado a delimitar las dimensiones y enumerar los diferentes pilares del sistema. El éxito ha sido desigual. Se ha avanzado en la concepción de los derechos de las personas pertenecientes a las minorías como parte integrante de los derechos humanos" (p.957).

En el preámbulo de la Declaración Universal de los Derechos Lingüísticos (1996, p.1) se establece que:

"...esta Declaración parte de las comunidades lingüísticas y no de los Estados, y se inscribe en el marco de refuerzo de las instituciones internacionales capaces de garantizar un desarrollo sostenible y equitativo para toda la humanidad y tiene como finalidad propiciar un marco de organización política de la diversidad lingüística basado en el respeto, la convivencia y el beneficio recíprocos"

De acuerdo a esta consideración, la Declaración entiende como denominación de lengua propia de un territorio "al idioma de la comunidad históricamente establecida en este espacio" (Art. 1) y considera también que: "en los casos en que diferentes comunidades y grupos lingüísticos concurren en un territorio compartido, el ejercicio de los derechos formulados en esta Declaración se tiene que regir por el respeto entre todos y dentro de las máximas garantías democráticas"(Art. 2). De acuerdo la Declaración se infiere que todos los indígenas tienen el derecho a ser atendidos en su lengua en los organismos oficiales. 
Tiene suma importancia lo que esta Declaración advierte en cuanto a los derechos lingüísticos, cuando refiere que: "Toda comunidad lingüística tiene derecho a que las actuaciones judiciales y administrativas, los documentos públicos y privados y los asientos en registros públicos realizados en la lengua propia del territorio sean válidos y eficaces y nadie pueda alegar el desconocimiento"(Art.15).

Del mismo modo la Declaración de las Naciones Unidas sobre los Derechos de los Pueblos Indígenas (2007) determina que: "los pueblos indígenas tienen derecho a practicar y revitalizar sus tradiciones y costumbres culturales. Ello incluye las artes visuales e interpretativas y literaturas, entre otras"(Art.11), lo cual ratifica cuando establece que: "Los pueblos indígenas tienen derecho a revitalizar, utilizar, fomentar y transmitir a las generaciones futuras sus historias, idiomas, tradiciones orales, filosofías, sistemas de escritura y literaturas, y a atribuir nombres a sus comunidades, lugares y personas y mantenerlos"(Art.13). En este instrumento internacional podemos observar como se consideran a los idiomas y a las tradiciones orales como derechos inherentes a los pueblos indígenas de la madre tierra y visibiliza en lo sustantivo la reivindicación de estas lenguas ancestrales.

La Declaración Americana sobre Derechos de los Pueblos Indígenas (2016) refiere que: "Los Estados reconocen y respetan el carácter pluricultural y multilingüe de los pueblos indígenas, quienes forman parte integral de sus sociedades"(Art. II).Y en el capítulo clave de la jurisdicción señala: "En consecuencia, tienen derecho sin discriminación, a igual protección y beneficio de la ley, incluso, al uso de intérpretes lingüísticos y culturales."(Art. XXII).

Los pueblos indígenas de Venezuela y Ecuador históricamente han sido objeto de dominaciones lingüísticas, atravesadas por relaciones de poder inherentes a las acciones unificadoras del mal denominado proceso civilizatorio, al punto de que se han impuesto en el inconsciente colectivo como algo normal, aun cuando ya son reconocidos sus derechos fundamentales por ambas constituciones nacionales.

Mucho se ha señalado respecto a que la soberanía popular potencia todo su valor en los idiomas y que la expresión lingüística en cuanto función comunicativa es órgano irreemplazable de la armonía social y humana. Sin embargo, el eficaz ejercicio de los derechos lingüísticos de las comunidades, pueblos y nacionalidades indígenas requiere de mecanismos institucionales y jurídicos que procuren la comunicación en sus propias lenguas con los demás ciudadanos y ciudadanas venezolanas y ecuatorianas, generando conciencia en toda la población sobre la realidad socio lingüística diversa de los dos países.

\section{Antecedentes}

Bajo un criterio sociolingüístico, Venezuela se ubica en la esfera cultural perteneciente a los Chibchas mientras que Ecuador se ubica en la esfera cultural 
de los Incas, y en el proceso de conquista española de América, originado en los siglos XVI y XVII. Las multiversas lenguas venezolanas: wayuu, barí y yukpas, y ecuatorianas: kichwas y shuar, entre otras, resistieron la imposición de la oralidad y la escritura española. No obstante, las lenguas andinas en general se ven amenazadas con desaparecer desde las reformas borbónicas de 1770 y sus políticas de castellanización.

En Venezuela el 96,2\% de la población indígena se concentra en 9 de las 23 entidades federales: Amazonas, Anzoátegui, Apure, Bolívar, Delta Amacuro, Monagas, Nueva Esparta, Sucre y Zulia. De allí que Allais (2004, p. 3) distingue como indígena a toda persona que: "hablara o hubiera oído hablar a su madre o abuela el idioma de su pueblo".

Históricamente, la expansión de la lengua quechua trajo consigo la extinción de otras expresiones que existían en Ecuador, lo que denota principalmente el proceso de la doble invasión que fue objeto este país, en un principio con la denominada conquista incaica y posteriormente con la también denominada conquista o descubrimiento de América que trae el castellano, proceso similar al doble patriarcado del que fue objeto la mujer ecuatoriana.

No obstante, según Fernández (2000), hay tres principios básicos que inspiran el reconocimiento y la protección de los derechos lingüísticos: "1) La libertad lingüística, derecho a la identidad lingüística. 2) La igualdad que posibilite la no discriminación a la diferencia y 3) El respeto al pluralismo".

Por ello, la protección de los idiomas tiene que ver con la defensa de los derechos humanos, y dentro de ellos la dignidad de las personas, no solo de la indígena sino de la dignidad humana no indígena. En este sentido, resalta Skutnabb-Kangas (1994) el concepto de "genocidio lingüístico": "la pérdida o muerte de la lengua no pasa porque sí, no es natural o inevitable. Más bien, es situada social, cultural y políticamente dentro de un amplio nexo de relaciones de poder dentro y entre grupos lingüísticos".

Como antecedente, en referencia al denominado Estado multilingüe con énfasis en el respeto a lenguas ancestrales de pueblos y nacionalidades indígenas, se encuentra como referente la Constitución política ecuatoriana de 1998 en la que se define a Ecuador como un Estado "social de derecho, soberano, unitario, independiente, democrático, pluricultural y multiétnico... El castellano es el idioma oficial. El quichua, el shuar y los demás idiomas ancestrales son de uso oficial para los pueblos indígenas, en los términos que fija la ley... El Estado respetará y estimulará su conservación y uso" (Congreso Nacional del Ecuador, 1998, Arts. 1-2).

Según Conejo (2008), Ecuador está conformado por población de etnia mestiza, indígena y afrodescendiente. La nacionalidad indígena habita en: a) la 
Costa con los pueblos awa, chachi, tsáchila y épera, b) la Sierra con el pueblo kichwa y en la c) Amazonía con el pueblo a'is (cofanes), sionas, secoyas, záparos, huaos, quichuas (actualmente kichwas) y shuara-ahuaras. Para Conejo (2008, p. 64) la educación ecuatoriana se denomina intercultural y bilingüe, pero en la práctica se ha caracterizado por generar una asimilación indiscriminada hacia las poblaciones indígenas, lo que ha limitado su desarrollo social, cultural y económico.

Esta asimilación indiscriminada, en palabras de Ayala (1994, pp. 203242) se produce por la formación de grupos de poder cuyo antecedente es la colonización española, uno de estos grupos de poder en el siglo XIX fue la iglesia católica. La relación Estado-Iglesia, con su monopolio ideológico cuya premisa fue que la religión oficial del Estado ecuatoriano fuera la católica, significó que todo ciudadano debía profesarla, además de que existiera un respaldo absoluto del Estado hacia la institución religiosa, de esa forma se le entregó el dominio de las tierras, la recaudación del tributo indígena y su diezmo, bibliotecas, medios de comunicación, imprenta, beneficencia, registro de nacimiento, matrimonios y defunciones. En sus manos estuvo la educación y la tarea de alfabetizar junto a la evangelización de los pueblos y nacionalidades indígenas.

La homogenización social en la República del Ecuador, constituida en 1830, significó que la influencia ideológica y el ejercicio de poder político, económico y social se acentuara en las clases dominantes con el proyecto político nacional criollo "monocultural". Bajo la influencia ideológica de la religión se sometía a la población indígena, campesina y menos favorecida a ideologías que sustentaban las condiciones de trabajo semejantes a la esclavitud a través de la creación de instituciones católicas de mano de obra como la mita, obrajes, encomiendas y concertaje. Estas prácticas de discriminación y desigualdad social negaban todo tipo de derechos de libertad hacia la población indígena, uno de estos derechos fue el respeto a su identidad cultural y educación junto a la práctica de su lengua ancestral (Ayala, 1994, p. 203-242).

Para Crespo y Vila (2014, p. 48) en la construcción de un Estado intercultural el giro decolonial o decolonización del poder y del saber debe poner un énfasis en la construcción de una educación intercultural ya que la "promoción de los saberes ancestrales es la transmisión de las lenguas originarias".

\section{Ordenamiento jurídico venezolano}

En Venezuela la legislación destinada a reconocer los derechos de los indígenas se encuentra dispersa en una cantidad de normas en su ordenamiento jurídico, que causan dificultades a la hora del ejercicio de estos derechos. Los factores geográficos y lingüísticos, así como su situación de aislamiento, los hacen grupos particularmente vulnerables a diferentes abusos. 
La Constitución de la República Bolivariana de Venezuela del año 1999, en su capítulo VIII, establece los derechos sociales, políticos, culturales y lingüísticoeducativos de los pueblos indígenas. Entre sus dispositivos constitucionales se hace referencia a que: "El Estado reconocerá la existencia de los pueblos y comunidades indígenas, sus idiomas y religiones"(Art.119); se proclama el derecho de los pueblos indígenas a "una educación propia y a un régimen educativo de carácter intercultural y bilingüe, atendiendo a sus particularidades socioculturales, valores y tradiciones"(art, 121); y en el artículo 9 se proclama el carácter oficial de los idiomas indígenas en sus respectivos ámbitos, los cuales "deben ser respetados en todo el territorio nacional por constituir el patrimonio cultural de la Nación y de la humanidad" (p. 2).

En este contexto constitucional, el Estado venezolano reconocerá la existencia de los pueblos y comunidades indígenas, su organización social, política y económica, sus culturas, usos y costumbres, idiomas y religiones, así como su hábitat y derechos originarios sobre las tierras que ancestral y tradicionalmente ocupan y que son necesarias para desarrollar y garantizar sus formas de vida. Le corresponde al ejecutivo nacional, con la participación de los pueblos indígenas, demarcar y garantizar el derecho a la propiedad colectiva de sus tierras, las cuales serán inalienables, imprescriptibles, inembargables e intransferibles de acuerdo con lo establecido en la Constitución y en la ley (Art.19).

Sin embargo, el Estado, a través de las políticas lingüísticas de los asuntos indígenas, en realidad, está imponiendo a estos pueblos el modelo oficial basado en el pensamiento occidental, en detrimento del principio de la autodeterminación y la autogestión de los indígenas venezolanos.

Posteriormente, entró en vigor la Ley Orgánica de Educación, en mayo de 2002, que crea el Consejo Nacional de Educación, Cultura e Idiomas Indígenas y la Ley Orgánica de Pueblos y Comunidades Indígenas de 2005. El Estado venezolano asume su deber de garantizar a su población indígena, el derecho a mantener y desarrollar su identidad étnica, lingüística y cultural. Se crea el Consejo Nacional de Educación, Culturas e Idiomas Indígenas como órgano asesor del ejecutivo nacional, con carácter permanente, para la consulta de las políticas de las comunidades indígenas. Entre sus funciones destaca, según Katarzyna Krzywicka (2011, p. 96): "la conservación del patrimonio histórico, cultural y lingüístico de los pueblos indígenas; facilitar el uso de los idiomas indígenas en habla y escritura como lenguas oficiales, preservando el reconocimiento de sus variedades gramaticales, léxicas y geográficas".

\section{Ordenamiento jurídico ecuatoriano}

Dentro del ordenamiento jurídico ecuatoriano se encuentran suscritos y ratificados instrumentos internacionales que vinculan al Estado con la promoción de los derechos culturales de pueblos y nacionalidades: 
El hito en materia de derechos humanos es la Declaración Universal de Derechos Humanos (ONU, 1948), que en su artículo 2 asegura la igualdad sin distinción ni discriminación en razón del origen étnico, nacionalidad, idioma, religión de una persona. El Pacto Internacional de Derechos Civiles y Políticos de la Organización de Naciones Unidas (ONU, 1966, Art. 1) asegura a pueblos y nacionalidades en todo el mundo su derecho a la libre determinación, así como el respeto a los derechos culturales, incluida lenguas ancestrales de pueblos y nacionalidades (ONU, 1966, Art. 2).

El Convenio 169 de la Organización Internacional del Trabajo sobre Pueblos Indígenas y Tribales asegura a los pueblos indígenas y tribales su libre determinación, así como el respeto de sus derechos culturales y a la transmisión oral de sus usos, costumbres y tradiciones (OIT, 1989, Art. 30), de igual manera lo señala Declaración de las Naciones Unidas sobre los Derechos de los Pueblos Indígenas del año 2007 (ONU).

La Convención sobre Protección y Promoción de la diversidad de las expresiones culturales de la Organización de las Naciones Unidas para la Educación resalta la obligación estatal de generar políticas culturales que propicien la creación, producción, difusión y disfrute del diálogo intercultural mediante el uso de la lengua ancestral (UNESCO, 2005, Art. 6).

La Constitución de Montecristi de 2008, define al Ecuador como: "un Estado constitucional de derechos y justicia, social, democrático, soberano, independiente, unitario, intercultural, plurinacional y laico"(Art.1).En su artículo 57 señala: "reconoce y garantizará a las comunas, comunidades, pueblos y nacionalidades indígenas, de conformidad con la Constitución y con los pactos, convenios, declaraciones y demás instrumentos internacionales de derechos humanos, los derechos colectivos", uno de estos derechos colectivos es el respeto y desarrollo de su lengua como herramienta de transmisión de saberes e interacción social.

En este sentido, uno de los derechos reconocidos a la población en general es la garantía constitucional de acceso a una justicia gratuita, imparcial y expedita para todas las personas, sin distinción de nacionalidad u origen, de forma específica en relación al idioma, interpretación y traducción cuando la persona lo requiera, establece que:

El derecho de las personas a la defensa incluirá las siguientes garantías: f) Ser asistido gratuitamente por una traductora o traductor o intérprete, si no comprende o no habla el idioma en el que se sustancia el procedimiento. Toda persona, en el momento de la detención, tendrá derecho a conocer en forma clara y en un lenguaje sencillo las razones de su detención, la identidad de la jueza o juez, o autoridad que la ordenó, la de quienes la ejecutan y la de las personas responsables del respectivo interrogatorio.(Constitución de la República del Ecuador, 2008, Art. 75-77) 
La Constitución de la República del Ecuador (2008) señala que el kichwa es un idioma oficial de relación intercultural:

El castellano es el idioma oficial del Ecuador; el castellano, el kichwa y el shuar son idiomas oficiales de relación intercultural. Los demás idiomas ancestrales son de uso oficial para los pueblos indígenas en las zonas donde habitan y en los términos que fija la ley. El Estado respetará y estimulará su conservación y uso (Art.2).

Sin embargo, esta oficialidad está supeditada a la entrada en vigencia de una ley especial que regule el uso oficial territorial de las lenguas indígenas tanto en áreas rurales como urbanas. La Comisión de Derechos Colectivos de la Asamblea Nacional trata el proyecto de Ley Orgánica de los Derechos Lingüísticos de Pueblos y Nacionalidades dada la necesidad de tener una normativa respecto a las lenguas de los pueblos indígenas de Ecuador.

El Estado ecuatoriano se denomina como plurinacional e intercultural. Para García (2009, pp. 15-24) el término interculturalidad se vincula a la necesidad de construir relaciones entre culturas, junto al diálogo de saberes diversos y el reconocimiento de los derechos de los pueblos, nacionalidades y etnias, respetados y valorados en sus tradiciones, cosmovisión y cultura, de forma íntegra sin prejuicios y estigmas, tomando en consideración sus identidades, expresiones y necesidades, a través de su idioma de interrelación.

En 1992 se promulga la reforma de la Ley de Educación en la cual se reconoce a la educación intercultural bilingüe, mediante la DINEIB (Dirección Nacional de Educación de Educación Intercultural Bilingüe) con la autonomía técnica, administrativa y financiera y el Modelo de Educación Intercultural Bilingüe (MOSEIB) que se expidió a través del Registro Oficial N. 278 de 17 septiembre del 1993 (Conejo 2008, p. 69)

El 2016, se promulga la Ley Orgánica de Cultura. Entre sus principios se destaca el de diversidad cultural, interculturalidad y buen vivir, garantizados a nivel constitucional (Asamblea Nacional del Ecuador, 2016, Art. 4). Sobre los derechos culturales, se protege el uso y la valoración de las lenguas ancestrales de relación intercultural, entre los deberes estatales se encuentra fomentar y crear espacios de reconocimiento y diálogo intercultural de saberes, uno de ellos su lengua ancestral (Asamblea Nacional del Ecuador, 2016, Art. 5); se reconoce que las manifestaciones culturales como costumbres, usos, creencias, conocimientos, cosmovisión y tradiciones ancestrales se transmitan de forma oral a través el uso de su lengua (Asamblea Nacional del Ecuador, 2016, Art. 80).

A nivel educativo se tiene la Ley Orgánica de Educación Intercultural que tiene como objetivo regular la educación inicial, primaria, secundaria y bachillerato 
a nivel nacional, al considerarse Ecuador como un Estado plurinacional e intercultural. Dentro de los principios filosóficos, conceptuales y constitucionales que rigen las actividades educativas, está la universalidad de la educación como aquel derecho fundamental, ineludible y accesible a todos sin distinción (Ministerio de Educación, 2017, Art. 2).Uno de los principios filosóficos de dicha ley denominada educación para el cambio resalta que es un instrumento de transformación social que contribuye a la construcción del país y el proyecto de vida de sus habitantes, así como de sus pueblos y nacionalidades. Sobre el principio constitucional de interculturalidad y plurinacionalidad se garantiza que los actores del sistema de educación brinden reconocimiento, respeto y valor a las diferentes nacionalidades, culturas y pueblos, propugnando la diversidad, a través del diálogo intercultural de saberes ancestrales, cuya herramienta de transmisión es su lengua. (Ministerio de Educación, 2017, Art. 2). El denominado plurilingüismo reconoce que uno de los derechos de los pueblos, nacionalidades, comunas, comunidades y nacionalidades es formarse en su propia lengua e idioma oficial de relación intercultural (Ministerio de Educación, 2017, Art. 2). El artículo 68 establece la vigilancia del Sistema de Educación Intercultural Bilingüe a través de la autoridad nacional Subsecretaría Intercultural Bilingüe (Ministerio de Educación, 2017, Art. 88).

El Reglamento de la Ley Orgánica de Educación Intercultural señala que las funciones de la Subsecretaría de Educación Intercultural Bilingüe son: generar políticas de pertinencia cultural y lingüística en el sistema educativo intercultural en Ecuador, así como coordinar las investigaciones lingüísticas del Instituto de Idiomas, Ciencias y Saberes Ancestrales de los pueblos y nacionalidades del Ecuador (Ministerio de Educación, 2016, Art. 247).

La Ley Orgánica de Educación Superior (2010) establece que:

"El derecho a la educación superior consiste en el ejercicio efectivo de la igualdad de oportunidades, en función de los méritos respectivos, a fin de acceder a una formación académica y profesional con producción de conocimiento pertinente y de excelencia. Las ciudadanas y los ciudadanos en forma individual y colectiva, las comunidades, pueblos y nacionalidades tienen el derecho y la responsabilidad de participar en el proceso educativo superior, a través de los mecanismos establecidos en la Constitución y esta Ley"(Art.4).

La Ley Orgánica de Educación Superior (LOES) considera como uno de los fines de este sistema la preservación y enriquecimiento de los saberes ancestrales y de la cultura nacional, así como también el principio de autodeterminación para la producción del pensamiento y el conocimiento en el marco del diálogo de los saberes, por lo cual las universidades deben estar articulados con el Plan Nacional de Ciencia y Tecnología, Innovación y Saberes Ancestrales, y con el Plan Nacional 
de Desarrollo (R.O.298, LOES, 2010, Arts. 8 y 145). Por ello, algunas universidades han considerado dentro de sus currículos la asignatura de kichwa como un idioma ancestral cuyo objetivo es conservar la comunicación multicultural y multilingüe para fortalecer la experiencia de la interculturalidad.

De igual forma, el artículo 7, k de la Ley Orgánica Reformatoria a la Ley Orgánica de Educación Superior (2018) señala que se debe: "Desarrollar, fortalecer y potenciar el sistema de educación intercultural bilingüe superior, con criterios de calidad y conforme a la diversidad cultural".

Por otra parte, encontramos el Proyecto de Ley Orgánica de Derechos Lingüísticos de los Pueblos y Nacionalidades del Ecuador, que tiene como objetivo reconocer y garantizar los derechos individuales y colectivos de los pueblos y nacionalidades con tradición lingüística propia. En consecuencia, los hablantes de lenguas ancestrales que por cualquier motivo tengan que comparecer ante los órganos de la Función Judicial tendrán derecho a utilizar su propia lengua de forma oral y escrita. Las autoridades responsables proveerán de intérpretes, traductores y/o defensores públicos que tengan conocimiento de su lengua y cultura. Así mismo, se velará por la inclusión en los currículos de estudio, de manera progresiva, de la enseñanza de por lo menos una lengua ancestral. Esto en coordinación con las autoridades competentes de todos los niveles de educación.

En el ámbito de la función judicial, desde el año 2009 se ha considerado que ésta trabaja en coordinación con la justicia indígena en un Estado pluralista, propugna la igualdad de los sistemas jurídicos que coexisten en el Ecuador, por el principio de diversidad cultural respeta el derecho propio de los pueblos y nacionalidades en sus usos y costumbres en el ámbito legal, junto a la intervención procesal de traductores, peritos antropólogos y especialistas del derecho indígena (Asamblea Nacional del Ecuador, 2009, Art. 344).

\section{Políticas públicas en Venezuela sobre lingüística indígena legal}

Durante la historia de Venezuela, según Pérez (2004, p. 618), "los indígenas venezolanos han pasado por situaciones de exclusión, discriminación y negación de sus derechos", en este sentido indica: "basta con mencionar, por ejemplo, el Decreto del 20 de agosto de 1840, firmado por el vicepresidente Carlos Soublette, donde se fijaban los requisitos indispensables en el trato con los guajiros, siendo uno de estos la reducción de los mismos".

El Consejo Nacional Indio de Venezuela (CONIVE), inicio una etapa de peticiones relacionadas con un cambio de política que apunta prioritariamente a una nueva legislación que garantice los derechos de los pueblos indígenas. Luis Jesús Bello (1999, p. 17),expresa: 
Como resultado de sus esfuerzos y los de sus seguidores, proyectos de ley han sido llevados al congreso para reforzar los derechos indígenas. Un "Proyecto de Ley de Comunidades, Pueblos y Culturas Indígenas" ha sido discutido en el Congreso, pero su aprobación no ha sido asegurada. Asimismo, ha sido introducido un proyecto de ley para incorporar en la ley venezolana el Convenio 169 de la Organización Internacional del Trabajo, sobre Pueblos Indígenas y Tribales.

Dentro de aquellas primeras propuestas, los pueblos indígenas presentaron al extinto Congreso de la República en el proceso de reforma constitucional la siguiente: "El idioma oficial es el castellano; las lenguas indígenas serán también oficiales en sus respectivas entidades federales". En Venezuela, hasta finales de los años noventa, la población indígena no fue protegida por la legislación indígena y no recibía la atención de las autoridades estatales administrativas y judiciales.

La política social del actual gobierno venezolano se rige por el principio de inclusión y participación de la población indígena en la ejecución de los programas de desarrollo. Es así como en 2003, se inicia la Misión Guaicaipuro, un programa especial destinado a satisfacer las necesidades de los indígenas.

Estadísticamente, el Censo Indígena que se llevó a cabo en Venezuela el año 2001, tuvo como objetivos: "Recopilar información del número de los hablantes de los diferentes idiomas indígenas, monolingüismo, disminución o aumento de hablantes de los múltiples idiomas indígenas o uno en particular, como se especifica en la Ficha técnica del Censo de Comunidades Indígenas" (Instituto Nacional de Estadística, 2001).

Para comprender los datos del Censo antes referido, Regnault (2005, p.13), señala que, de acuerdo con estos datos,

"la población indígena en Venezuela alcanza 534.816 habitantes, distribuidos entre 36 pueblos principales. Los pueblos indígenas, en general, se clasifican en pueblos consolidados, como, por ejemplo, los Yanomamis, los Waraos, los Wayuu, los Piaroas; pueblos emergentes, o en reconstrucción, con una identidad difusa, tales como los Chaimas, los Waiqueríes, los Cumanagotos; con un tercer grupo de personas que conservan rasgos culturales y fenotípicos indígenas, pero no saben decir con exactitud a qué etnia pertenecen.

Dicho autor continúa planteando que el primer gran obstáculo en la construcción de Venezuela como un Estado Nación, fue replicar modelos extranjeros que no consideraban su contexto multicultural, multiétnico y plurilingüe. No pensar un país desde su diversidad, sino buscando la uniformización. Se olvida que la democracia se construye desde la diferencia y que en el disenso se construyen propósitos comunes. En julio de 2005 fue creada la Oficina de Enlace con las Comunidades Indígenas en el marco de la actividad del Ministerio del Poder Popular para la Cultura. 
Siguiendo a Katarzyna Krzywicka (2011, p. 78), en Venezuela los partidos políticos indígenas tienen carácter regional, a excepción del ya mencionado CONIVE, una organización de alcance nacional con objetivos políticos:

Los partidos más importantes en el estado Amazonas son: Pueblos Unidos Multiétnicos de Amazonas (PUAMA), Movimiento Unido de Pueblos Indígenas (MUPI) y la Fundación para la Capacitación, Integración y Dignificación del Indígena (FUNDACIDI). En el estado Zulia funciona el Movimiento Indígena Autónomo del Zulia (MIAZULIA). Una característica notable de los partidos indígenas son las divisiones internas de carácter étnico, poca experiencia política y penetración ideológica.

Finalmente, como marco político se establece el Proyecto Nacional Simón Bolívar, primer plan de corte socialista, con el cual se produce la penetración ideológica de las comunidades indígenas y su subordinación a los objetivos del gobierno, vulnerando los derechos culturales lingüísticos de los pueblos indígenas, imponiéndose el proyecto meramente político.

\section{Políticas públicas en Ecuador sobre lingüística indígena legal}

En el siglo XX, según Conejo (2008 p. 65) "el desarrollo histórico de la educación intercultural bilingüe se inicia en Ecuador con experiencias educativas que atendieron a la población indígena teniendo en cuenta sus características sociales y culturales, y revalorizaron sus lenguas ancestrales, sin necesidad de recurrir al castellano", entre estas experiencias se destacan las escuelas indígenas en Cayambe, con la maestra Dolores Cacuango, quien con apoyo de otras mujeres de la ciudad de Quito y mujeres dirigentes indígenas organizaron escuelas indígenas ubicadas en el cantón Cayambe, provincia de Pichincha y en la provincia de Imbabura. Una de las características de esta iniciativa fue que en estas escuelas ubicadas en comunidades indígenas enseñaban maestros utilizando su lengua materna; la última escuela funcionó hasta 1963 con la Junta Militar.

Las Escuelas Radiofónicas Populares del Ecuador (ERPE) se crean en 1964 en la provincia de Chimborazo y Pichincha en Tabacundo, su objetivo fue alfabetizar a adultos mayores de habla kichwa (Conejo 2008, p. 66).

El Sistema Radiofónico Shuar (SERBISH), se crea en 1973 como escuelas radiofónicas de los pueblos Shuar/Achuar en la región amazónica, abarcó la educación primaria como la secundaria. En el ámbito de educación superior se encuentra el Instituto Pedagógico Intercultural Bilingüe y el Instituto Normal Bilingüe Intercultural, cuya cobertura se ha extendido hasta la región de la costa: "emplean la lengua materna y el español en materiales para la primaria y secundaria producidos en los dos idiomas... uno de los aspectos importantes ha sido la formación de maestros indígenas y auxiliares radiofónicos" (Ibid, p.67). 
Las escuelas indígenas de Simiatug, en la provincia de Bolívar en la parroquia Simiatug, funcionan con el apoyo de la organización indígena Fundación Runacunapac Yachana Huasi. Ha elaborado un documento para la "alfabetización de los niños utilizando el sistema kichwa de escritura unificada". La dificultad que enfrentan es la existencia de niños que no han adquirido el kichwa como lengua materna, por lo que se requiere formar maestros para enfrentar esta situación" (Ibid. p. 67).

El Sistema de Escuelas Indígenas de Cotopaxi (SEIC), creado en 1974 con el auspicio de religiosos salesianos, abarca comunidades de la provincia de Cotopaxi. En las escuelas utilizan la lengua materna para su educación, con maestros de las propias comunidades, y en la secundaria el colegio Jatari Unancha cuya modalidad es semipresencial (Ibid. p. 67).

El Proyecto Alternativo de educación Bilingüe de la CONFENIAE (PAEBIC), se crea en 1986 en ocho escuelas que funcionan en la provincia de Napo y Pastaza (Ibid. p. 68).

Según Grzech (2017) se encuentran varias iniciativas a nivel macro, meso y micro y citando a Kaplan y Baldauf (1997). Entre la planificación macro que se desarrolla a nivel estatal e internacional, se resalta la creación del modelo de educación intercultural a cargo de la Subsecretaría de Educación Intercultural (Ministerio de Educación, s.f.).

El Instituto de Idiomas, Ciencias y Saberes Ancestrales (IICSAE, 2016) realizó actividades a nivel nacional, regional y local entre las que se destacan"1700 diccionarios educativos kichwa -castellano impresos, 1700 diccionarios educativos ilustrados shuar chicham impresos, compilación de materiales educativos de enseñanza de la lengua sapara y la creación de la plataforma didáctica oficial del IICSAE"(p.8).

En el nivel meso, a nivel regional, en la región amazónica en las escuelas de las regiones con una mayoría de alumnos indígenas, señala Grzech (2017), "la enseñanza se desarrolla en la lengua de la mayoría indígena local, aunque la instrucción en kichwa se limita en muchas zonas a la educación primaria, las escuelas kichwahablantes existen en toda la provincia de Napo" (p.26), una de las consideraciones a tomar en cuenta es que la enseñanza se realiza a través del idioma kichwa unificado y no en sus variantes; lo cual critica Grzech ya que puede generar un proceso de eliminación de la variante de la lengua kichwa por su desuso y propiciar la suplantación lingüística de forma rápida hacia el español:

"A nivel estatal, el kichwa tiene una escasa presencia en los medios. La televisión ecuatoriana transmite prácticamente solo programas en español y la presencia del kichwa es muy ocasional. Cuando aparecen kichwa-hablantes, se trata en su mayoría de las comunidades andinas que usan el kichwa unificado o las variedades andinas... el estado 
ecuatoriano parece tener una política lingüística favorable hacia el kichwa. El idioma tiene un estatus oficial reconocido en la Constitución; los documentos oficiales se traducen al kichwa, y los niños de las familias kichwa-hablantes tienen acceso a la educación en kichwa. Sin embargo, el estado parece no distinguir entre el kichwa unificado y sus respectivas variedades locales, que son los verdaderos vernáculos de sus ciudadanos. En consecuencia, la política y la planificación a nivel estatal fomentan el uso de la variedad estándar, pero no brindan apoyo a los dialectos locales, incluyendo el kichwa de Alto Napo."(p. 27).

La participación política de los movimientos indígenas ecuatorianos en la Asamblea Constituyente de 1988 y el levantamiento indígena de 1990 marcaron un hito histórico en los derechos civiles y políticos de la población indígena ecuatoriana.

Según los datos del censo de 2001, solo el $15 \%$ de la población indígena sería monolingüe vernácula. En la distribución del poder administrativo, las nacionalidades y sus representantes quedan en minoría y solo están representadas por el Consejo Plurinacional del Sistema Intercultural Bilingüe.

Finalmente, Fernández (2000, p.9) sostiene que: "El reconocimiento de los derechos lingüísticos y la protección de las lenguas propician el amparo de los derechos fundamentales en su sentido más amplio, y previenen la aparición de conflictos, internos e internacionales".

\section{Estudios sobre lenguas ancestrales en Ecuador}

Abordando el desarrollo y revalorización de lenguas ancestrales en Ecuador se debe resaltar según Conejo (2008) la actividad del Instituto Lingüístico de Verano, organismo no gubernamental estadounidense que trabajó desde 1952 hasta 1981, en comunidades localizadas en las tres regiones del Ecuador continental, "uno de sus objetivos fue evangelizar y traducir la Biblia a las lenguas ancestrales" (p. 67).

Así mismo, el referido autor señala a la Misión Andina en 1956 que ingresó a la provincia de Chimborazo con apoyo financiero de la OIT, que: "a principio de los años 70 preparó cartillas de lectura de la lengua kichwa, y de varias lenguas ancestrales de los pueblos Salasaca, Imbabura y Chimborazo" (Ibid. p. 69).

Desde la visión universitaria, según Conejo (2008), la Pontificia Universidad Católica del Ecuador en el año 1978 inicia el programa de alfabetización kichwa a través de su Instituto de Lenguas y Lingüística hasta 1986. Entre 1974 y 1984 funcionó la licenciatura en lingüística kichwa; la Facultad Latinoamericana de Ciencias Sociales en Ecuador emprendió un proyecto de Archivo de Lenguas y Culturas del Ecuador (Ibid. p. 67). 
En el contexto de la globalización, con las tecnologías de la información, la carrera de Ingeniería de Sistemas Informáticos de la Universidad Tecnológica Israel, el 2016, publica el trabajo de titulación sobre el desarrollo de un sistema móvil para el aprendizaje inicial de la lengua ancestral Shuar, esta constituye una propuesta educativa que integra la educación junto a la informática, con el fin de fomentar la enseñanza-aprendizaje de la lengua shuar chicham, aplicando la metodología digital a través de dispositivos móviles y el uso de tecnología en las aulas virtuales y presenciales, "esta puede dar excelentes resultados en el proceso educativo para el desarrollo de la lecto-escritura de los niños y niñas, en su propia lengua" (Ibid. p.IV).

Del mismo modo la Universidad de Otavalo desde el 2016, en el rediseño de sus carreras de pregrado, en las mallas curriculares incorporó el kichwa como parte del proceso de enseñanza aprendizaje con enfoque intercultural. Todos los estudiantes se forman en el idioma ancestral cursando 4 niveles de aprendizaje, los profesores del centro de idiomas de la universidad son originarios del pueblo kichwa Otavalo. Es así como dentro de la educación continua se han creado cursos del idioma kichwa dirigidos a la comunidad otavaleña (Universidad de Otavalo, 2019).

Mejeant (2001) resalta que existen estudios sobre lenguas ancestrales y sus resultados:

"La Pontificia Universidad Católica del Ecuador, a través de Consuelo Yánez y Fausto Jara elaboraron un método para enseñanza del quichua en que se empleaba esta escritura. Un estudio académico de la fonología de las diez lenguas indígenas del Ecuador está disponible en el libro Lingüística Aplicada a la Educación Intercultural Bilingüe, Colección de Antropología Aplicada No. 12 de Luis Fernando Gárces V.y Catalina Alvarez Palomeque. La recopilación del corpus lingüístico más importante es el realizado por Louisa Stark entre septiembre de 1971 y agosto de 1975. Este trabajo poco conocido en los medios lingüísticos comprende un vocabulario de unas 500 palabras. Existe la Organización de la Nacionalidad Zapara del Ecuador ONAZE con oficina en la Shell y con influencia evangélica en la localidad de Balzaura. Un dato común del nombre de los idiomas indígenas ecuatorianos es que unen la noción de gente con lengua (p. 10).

Resalta, Mejeant (2001) que: "existen 10 lenguas indígenas de los pueblos y nacionalidades indígenas que se conservan dentro de sus comunidades". A continuación se presenta una descripción de los pueblos indígenas hablantes cuyo orden de prelación se basa en el número aproximado de hablantes al año 2000 (p. 1) y su actualización al 2016 según el Instituto de Idiomas, Ciencias y Saberes Ancestrales como ente oficial: 
Tabla 1: Lenguas ancestrales en Ecuador

\begin{tabular}{|c|c|c|c|c|c|c|}
\hline $\mathbf{N}$ & Pueblo & Lengua & Ubicación & Alfabeto & Población & $\begin{array}{l}\text { Número de } \\
\text { hablantes }\end{array}$ \\
\hline 1 & Kichwa & Kichwa & $\begin{array}{c}\text { Callejón interandino } \\
\text { y en la mayoría } \\
\text { del Oriente: } \\
\text { Imbabura, Pichincha, } \\
\text { Bolívar, Cotopaxi, } \\
\text { Tungurahua, } \\
\text { Chimborazo, Cañar, } \\
\text { Azuay, Loja, Napo; } \\
\text { Sucumbíos, Orellana, } \\
\text { Pastaza y Zamora } \\
\text { Chinchipe }\end{array}$ & $\begin{array}{l}a, c, c h, t^{*}, i, h,(j), k, l \\
\|, m, n, \tilde{n}, p, q, r, s, s h, \\
t, u, w, y .(21 \text { letras) }\end{array}$ & 328.149 & $\begin{array}{l}230.659 \\
\text { hablantes }\end{array}$ \\
\hline 2 & Ahuar & $\begin{array}{l}\text { Shuar- } \\
\text { Achuar } \\
\text { existe otro } \\
\text { subdialecto } \\
\text { conocido } \\
\text { como } \\
\text { shiwiar }\end{array}$ & $\begin{array}{l}\text { Zamora Chinchipe, } \\
\text { Morona Santiago } \\
\text { y Pastaza, Napo, } \\
\text { Sucumbíos y en la }\end{array}$ & $\begin{array}{l}\text { Shuar: a, a, aa, aa, ch, } \\
\text { e, e, ee, ee, i, i, ii, ii, j, } \\
\text { k, m, n, p, r, s, sh, t, ts, } \\
\text { u, u, uu, uu, w, y. ( } 29 \\
\text { letras). } \\
\text { Achuar: a, aa, ch, e, } \\
\text { ee, i, ii, j, k, m, n, p, r, } \\
\text { s, sh, t, ts, u, uu, w, y, } \\
\text { (21 letras) }\end{array}$ & 79.709 & $\begin{array}{l}58.194 \\
\text { hablantes }\end{array}$ \\
\hline 3 & $\begin{array}{l}\text { Chachi o } \\
\text { Cayapas }\end{array}$ & Cha'Palasa & $\begin{array}{l}\text { Río Cayapas, del río } \\
\text { Canandé y de Muisne } \\
\text { en Esmeraldas }\end{array}$ & $\begin{array}{l}a, \text { aa, b, ch, d, dy, e, } \\
\text { ee, f, g, i, ii, j, k, I, ll, } \\
\text { m, n, ñ, p, r, s, sh, t, ts, } \\
\text { ty, u, uu, v, y, (30 letras) }\end{array}$ & 10.222 & $\begin{array}{l}8.463 \\
\text { hablantes }\end{array}$ \\
\hline 4 & Awá & Awapit & $\begin{array}{c}\text { Fronteras de Carchi } \\
\text { y Esmeraldas y } \\
\text { al noroccidente } \\
\text { de la provincia de } \\
\text { Imbabura }\end{array}$ & $\begin{array}{l}a, \hat{a}, b, c h, c h h, d, d y, \\
e, \hat{e}, f, g, i, i, j,(h), k \text {, } \\
\text { kh, m, n, ñ, o, ô, p, ph, } \\
\text { s, sh, t, th, ts, tsh, u, û, } \\
v, y, z,(35 \text { letras) }\end{array}$ & 5.513 & $\begin{array}{l}2.169 \\
\text { hablantes }\end{array}$ \\
\hline 5 & $\begin{array}{c}\text { A'i } \\
\text { (Cofán) }\end{array}$ & A'Ingae & $\begin{array}{l}\text { Ríos Aguarico y San } \\
\text { Miguel, provincia de } \\
\text { Sucumbíos }\end{array}$ & $\begin{array}{l}\text { a, an, b, c, cc, ch, chh, } \\
d, d y, e, e n, f, g, i, \text { in, } \\
\text { j, m, n, ñ, o, on, p, pp, } \\
\text { qu, qqu, s, sh, t, tt, ts, } \\
\text { tss, u, un, v, y, z, (36 } \\
\text { letras). }\end{array}$ & 1485 & $\begin{array}{l}1.114 \\
\text { hablantes }\end{array}$ \\
\hline 6 & Tsa'chila & Tsafiqui & $\begin{array}{l}\text { Zona de Santo } \\
\text { Domingo de los } \\
\text { Tsáchilas }\end{array}$ & $\begin{array}{l}a, c h, d, e, f, g, i, j, k, l \\
\text { m, n, ñ, o, p, r, s, sh, t, } \\
\text { ts, u, w, y. (23 letras). }\end{array}$ & 2.956 & $\begin{array}{l}2.191 \\
\text { hablantes }\end{array}$ \\
\hline 7 & Waorani & Waotededo & $\begin{array}{c}\text { Ríos Yasuní, } \\
\text { Cononaco. Nushiño } \\
\text { y Curaray de las } \\
\text { provincias de Napo y } \\
\text { Pastaza. }\end{array}$ & $\begin{array}{l}a, a ̈, b, c, d, e, e ̈, a e \\
\text { aë, g, i, ï, o, ö, p, qu, t, } \\
\text { w, y (19 letras). }\end{array}$ & 2.416 & $\begin{array}{l}2.083 \\
\text { hablantes }\end{array}$ \\
\hline 8 & $\begin{array}{l}\text { Siona y } \\
\text { Secoya }\end{array}$ & $\begin{array}{l}\text { Paicoca } \\
\text { o dialecto } \\
\text { conocido } \\
\text { como tetete }\end{array}$ & $\begin{array}{l}\text { Ríos Aguarico } \\
\text { y Cuyabeno en } \\
\text { la provincia de } \\
\text { Sucumbíos }\end{array}$ & $\begin{array}{l}\text { a, a, c, d, e, e, ë, ë, hu, } \\
\text { i, i, j, m, n, ñ, o, o, p, } \\
\text { qu, r, s, t, ts, u, u, y, ( } 27 \\
\text { letras). }\end{array}$ & $\begin{array}{l}\text { Siona } 611 \\
\text { Secoya } 689\end{array}$ & $\begin{array}{l}\text { Siona } 380 \\
\text { hablantes } \\
\text { Secoya } 556 \\
\text { hablantes }\end{array}$ \\
\hline
\end{tabular}




\begin{tabular}{|c|c|c|c|c|c|c|}
\hline 9 & $\begin{array}{c}\text { Epera } \\
\text { (embera) }\end{array}$ & $\begin{array}{c}\text { Epera } \\
\text { Pedede }\end{array}$ & $\begin{array}{l}\text { Provincia de } \\
\text { Esmeraldas }\end{array}$ & $\begin{array}{l}\text { a, â, aa, b, ch, d, e, ê, } \\
\text { ee, i, î, ii, i, î, k, kh, m, } \\
\text { n, o, ô, oo, p, ph, r, s, } \\
\text { t, th, u, û, uu, w, y, (32 } \\
\text { letras) }\end{array}$ & 6.416 & $\begin{array}{l}4.020 \\
\text { hablantes }\end{array}$ \\
\hline 10 & $\begin{array}{l}\text { Curaray } \\
\text { o pueblo } \\
\text { Zaparo }\end{array}$ & Kayapi & $\begin{array}{c}\text { Provincia de Pastaza } \\
\text { y en Balzaura en el } \\
\text { noroeste de Pastaza }\end{array}$ & $\begin{array}{l}a, a^{0}, c h, i_{1} i^{0}, j, k, m, n, \\
p, r, s, \text { sh, t, ts, u, } u^{0}, \\
w, y, z h^{*} .(21 \text { letras). La } \\
\text { zh solo se encuentra } \\
\text { en préstamos del } \\
\text { kichwa. }\end{array}$ & 559 & 462 hablantes \\
\hline
\end{tabular}

Fuente: Mejeant, 2001, pp. 1-10; Instituto de Idiomas, Ciencias y Saberes Ancestrales,2016, p. 12.

Por su parte, Salazar (2015) señala que existen trece lenguas indígenas que se hablan en Ecuador: "Achuar Chicham, Awapit, A'ingae, Cha'palaa, Kichwa, Paicoca, Baicoca, Shiwiar Chicham, Shuar Chicham, Sia Pedee, Tsa'fiki, Wao Tededo y Sapara" (p. viii). Las lenguas ancestrales que se suman son la achuar chicham, baicoca y shiwar chicham, frente al análisis presentado en la Tabla 1. El nombre de las lenguas suele escribir y pronunciarse diferente o incluso se las considera iguales como es el achuar chicham con el shuar chicham, por un parte, no se ha estandarizado su nombre y tampoco su alfabeto, o se define sus ramificaciones y diferencias (en el caso de las lenguas kichwa, shuar y achuar).

Sobre el análisis del uso de estas lenguas ancestrales en Ecuador, el Ministerio de Relaciones Exteriores, en base a investigaciones realizadas por la Pontificia Universidad Católica del Ecuador, señala que en Ecuador existen: "18 pueblos y 14 nacionalidades con su propia lengua indígena: 8 de ellas en peligro inminente de extinción, tales como Cofán (aingae), Siona-Secoya (paicoca), Kicwha, Shuar, Wao, Sapara, Andoa, Sáfiqui".(Consejo Nacional para la Igualdad de Pueblos y Nacionalidades, 2019).

Como iniciativa social en la ciudad de Quito se ha creado la Escuela Intercultural Bilingüe de Quito o CEDEIB-Q como respuesta a una necesidad de los actores sociales, en este sentido Crespo y Villa (2014) señalan:

"Como espacio de reivindicación cultural de los pueblos y nacionalidades indígenas que habitaban la ciudad, la institución educativa capaz de afirmar el valor de su lengua y su cultura se ha consolidado como un dispositivo vivo de diálogo intercultural...se ha convertido en una herramienta autogestionada e imaginada por los propios actores, para beneficiar a una comunidad históricamente discriminada, cuya identidad ha sido subalternizada" (p. 84). 
Relatan Crespo y Vila (2014) "que con la emigración de familias kichwa a la ciudad de Quito en los años 1970 se genera una dificultad para la transmisión de su cultura, saberes ancestrales, educación a sus hijos en su lengua materna". En este sentido se debe recordar que el contexto urbano rechaza lo indígena por el idealizado blanqueamiento. Es así que el referido autor dice que: "Ias familias, padres, madres y profesores con el propósito de educar a sus hijos toman el edificio del antiguo Colegio Central Técnico abandonado ubicado junto al Mercado San Roque" (p. 84).

En el Napo, Grzech (2017) señala quela lengua kichwa actualmente con casi 10 millones de hablantes "es la familia más grande de las lenguas indígenas de América del Sur" (p. 22), esta lengua tiene variantes, una de ellas se usa como lengua de dialogo a nivel comunitario en la provincia de Napo, dentro de los resultados de su investigación encuentra que:

"El idioma local apenas se transmite a los niños; muchos kichwas de la zona estudian y trabajan en la capital provincial o para las compañías petrolíferas activas en la provincia, la lengua dominante del contacto social es el español; muchos profesores que trabajan en las escuelas de las comunidades selváticas de la provincia con un dominio del kichwa no siempre les permite dar clases en el idioma local; aunque los espectadores adultos conversan entre sí en la variante local del kichwa, los jóvenes y los niños tienden a comunicarse en español. Los actos se desarrollan tanto en el kichwa de Alto Napo como en kichwa unificado y en español. La población kichwa percibe el español como una lengua que facilita la movilidad social y el éxito profesional; la mayoría de los ancianos (mayores de 60 años de edad) de las comunidades de la rivera del Napo tiene un cierto dominio del español. Los adultos y adultos mayores (20-60 años de edad) son casi todos bilingües, mientras que entre la gente más joven el español domina cada vez más, muchos solo tienen un conocimiento pasivo de la lengua y se comunican entre sí y con los mayores en español. Los niños, aunque entienden frases básicas de kichwa, pueden considerase monolingües de español".(p. 25-26).

De su análisis, en base a la escala gradual de interrupción intergeneracional menciona Grzech (2017) que el kichwa mantiene un nivel constitucional de reconocimiento oficial para la interacción cultural y ha sido usado como lengua ancestral a nivel educativo primario e incluso en medios de comunicación a escala nacional por lo que el kichwa alcanza el nivel 2 de la escala a nivel nacional y a nivel regional y local de comunidades en las que se imparte el kichwa en el nivel educativo se encuentra en el nivel 1 (p. 30). 


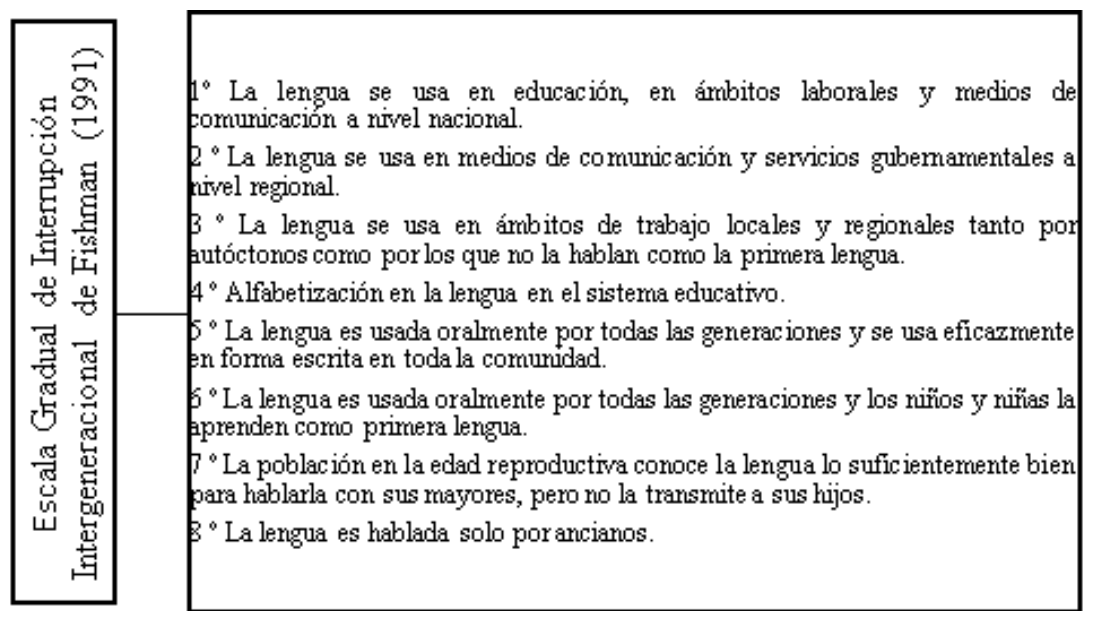

Fuente: Grzech, 2017, p. 30.

En el caso de las dos iniciativas mencionadas se puede resaltar que son el resultado de un trabajo autogestionado de pueblos y nacionalidades indígenas, como actores primordiales que desean transmitir sus saberes y conocimientos a sus hijos de forma intergeneracional usando su lengua ancestral como herramienta de interrelación.

En el 2019 el Ecuador frente a la situación de las lenguas ancestrales indígenas y su posible declive e incluso extinción, como Estado miembro de la Organización de Naciones Unidas, coordinó la creación del Plan de Acción del año internacional como resultado del Foro Permanente sobre Cuestiones Indígenas, realizado el año 2018;es así que se propuso promover el Año Internacional de las Lenguas Indígenas (AILI). (Consejo Nacional para la Igualdad de Pueblos y Nacionalidades, 2019).

En este sentido, el Consejo Nacional para la Igualdad de Pueblos y Nacionalidades (2019) como miembro de la mesa interinstitucional junto al "Ministerio de Educación, Secretaría de Educación Intercultural Bilingüe, Cancillería y Senplades" propuso que entre las acciones a realizar están:

"Crear un Comité para trabajar varios temas sobre las Lenguas indígenas, con la posibilidad de proponer se declare el Decenio de las Lenguas Indígenas 2020-2029. Realización de 2 eventos a nivel nacional y 3 micros eventos en territorios de Pueblos y Nacionalidades con fechas tentativas 21 de febrero/21 de marzo. En provincias especificas donde se realizará el anclaje en territorio del CNIPN como Esmeraldas y Guayaquil, 
al igual que en provincias de Sierra Sur y de la Amazonia. Establecer acuerdos entre Academia-Estado-CNIPN para la ejecución de un proyecto de capacitación a funcionarios públicos en temas de políticas lingüísticas". (Consejo Nacional para la Igualdad de Pueblos y Nacionalidades, 2019).

No obstante, el Grupo Especial de Expertos sobre las Lenguas en Peligro (2003), convocado por la UNESCO, en el documento sobre Vitalidad y peligro de desaparición de las lenguas señala que, frente a la situación de las lenguas ancestrales en todo el mundo, con el fin de promover y asegurar su permanencia, las medidas deben ser:

1. Formación lingüística y pedagógica básica: Proporcionar a los profesores de lenguas formación en lingüística básica, técnicas y métodos de enseñanza de lenguas, planificación de programas de estudio y preparación de materiales didácticos. 2. El desarrollo sostenible de la alfabetización y de las capacidades locales de documentación: Formar a trabajadores lingüísticos locales en el desarrollo de reglas ortográficas si fuera necesario, en la lectura, la escritura y el análisis de sus idiomas y en la producción de material pedagógico. La alfabetización es útil para la enseñanza y el aprendizaje de tales lenguas. 3. El fomento y desarrollo de una política lingüística nacional: Las políticas lingüísticas nacionales deben favorecer la diversidad, sin excluir la conservación de las lenguas en peligro. En la formulación de políticas lingüisticas nacionales deberían participar activamente más sociólogos y especialistas en ciencias humanas, así como los hablantes de las lenguas amenazadas. 4. El fomento y desarrollo de una política educativa: En el sector de la educación son ya numerosos los lingüistas dedicados a la puesta en práctica de programas de enseñanza de la lengua materna, que son cada día más populares. 5. La mejora de las condiciones de vida y el respeto a los derechos humanos de las comunidades de hablantes: Los especialistas en documentación lingüística, aunque no participen directamente en el desarrollo económico y social, pueden ayudar a los gobiernos a identificar a las poblaciones marginadas. Los lingüistas y los educadores pueden ser mediadores cruciales si ayudan a esas comunidades a reivindicar sus derechos lingüísticos y otros derechos humanos.(Grupo Especial de Expertos sobre las Lenguas en Peligro, 2003).

El fomento de la educación básica en la enseñanza y aprendizaje de la lengua materna de la población y grupos minoritarios se hace a través de la formación pedagógica a los profesores, como eje central en la política educativa intercultural y multilingüe de un Estado. Los programas de alfabetización no solo deben enfocarse en el uso y difusión de la enseñanza de lenguas convencionales 
como es el español, y en el caso de pueblos y nacionalidades indígenas el kichwa. La política lingüística a nivel nacional y local, debe utilizar el enfoque de la interculturalidad, permitir que los estudios de sociólogos y especialistas en ciencias humanas, y hablantes de las lenguas ancestrales participen activamente como garantía de sus derechos culturales y derechos colectivos. Además, la política pública para el fomento de lenguas ancestrales, siempre será una política educativa.

Tomando como base las particularidades sociales y culturales, se puede estudiar los fenómenos vinculados al desuso de una lengua por otra, lo que promueve la estandarización de un idioma frente a la extensión de otro idioma.

\section{Análisis comparativo entre Ecuador y Venezuela}

En el análisis de la normativa vinculada a la promoción y difusión de lenguas ancestrales junto a las políticas públicas de fomento cultural vinculado al uso de los dialectos y sus ramificaciones en los Estados ecuatoriano y venezolano se identifican algunos criterios:

Los Estados se vuelven actores secundarios en el momento en que promulgan un marco normativo vinculante que obliga al respeto, difusión y promoción del uso de lenguas ancestrales como parte del enfoque de interculturalidad, por otra parte, crean políticas públicas cuyo objetivo es promover el uso de lenguas ancestrales estándar en ambos Estados (kichwa, shuar, etc), pero se omite la necesidad de impulsar bajo el principio de igualdad formal y material y la no discriminación de todas las lenguas ancestrales y sus ramificaciones.

Las lenguas ancestrales de todos los pueblos y nacionalidades en ambos Estados requieren la necesidad de que exista una mayor difusión. Por una parte, porque se debe reconocer que la transmisión de saberes utiliza como instrumentos a la educación y a las lenguas ancestrales. Y, por otra parte, porque siendo estas lenguas ancestrales diversas, como en el caso del kichwa al ser polinómica, al haberse unificado se genera una estandarización que amenaza la transmisión intergeneracional de sus lenguas vernáculas, conflicto que a nivel local en comunidades y pueblos ancestrales permite que se sustituya la lengua ancestral/ materna por el español.

La transmisión intergeneracional de las lenguas ancestrales es un factor importante que ha influido para el fomento de un idioma ancestral y que generalmente no se ha fomentado como prioritario:

“(...) casi toda la heterogeneidad lingüística del mundo es custodiada por un número muy pequeño de personas. Incluso idiomas con 
muchos millares de hablantes ya no se enseñan a los niños; al menos el $50 \%$ de las más de seis mil lenguas del mundo están perdiendo hablantes. Según nuestros cálculos, cerca del 90\% de todas las lenguas podrían ser sustituidas por lenguas dominantes de aquí a finales del siglo XXI. Muchos pueblos indígenas, asociando su condición social desfavorecida con su cultura, han llegado a creer que no merece la pena salvaguardar sus lenguas. Abandonan su lengua y su cultura con la esperanza de vencer la discriminación, asegurarse un medio de vida y mejorar su movilidad social o integrarse en el mercado mundial."(Grupo especial de expertos sobre las lenguas en peligro, 2003).

En Ecuador y Venezuela existen lenguas en desuso, lo que las pone en peligro de extinción; especialmente porque los materiales didácticos de enseñanza y aprendizaje no han sido elaborados o requieren ser actualizados.

\section{La interculturalidad propuesta por el Observatorio Jurídico de la Universidad de Otavalo}

El Observatorio Jurídico para la Prevención de Derechos Colectivos de la carrera de Derecho de la Universidad de Otavalo, ubicado en la provincia de Imbabura-Ecuador, es un centro de investigación continua y permanente en temas relacionados con la vulneración de derechos en grupos vulnerables, por esto, se consideró pertinente efectuar una pequeña contribución a esta investigación con el análisis de su grupo focal integrado por docentes investigadores y estudiantes observadores de la problemática de los derechos lingüísticos del pueblo Kichwa asentado en el Ecuador, en relación con la omisión que desde hace más de diez años ha incurrido la Asamblea Nacional al no legislar en la ley Orgánica que se requiere.

Siguiendo a la Guía Práctica para la aplicación de Derechos Lingüísticos de las minorías Lingüísticas (2017, p.31) podemos ubicar la utilidad de la propuesta del Observatorio jurídico, cuando indica que:

"Las consecuencias de no utilizar un idioma que entiendan las personas involucradas en el sistema de justicia son extremadamente graves, en particular en relación con el derecho a un juicio justo, tal y como aparece consagrado en el derecho internacional, según el cual en los procesos penales y otras actuaciones similares debe proporcionarse siempre interpretación y traducción gratuitas con un nivel mínimo y adecuado destinado a las personas acusadas o detenidas que no entiendan el idioma utilizado por los funcionarios judiciales o encargados de hacer cumplir la ley, a fin de que puedan ejercer su derecho a tener una defensa y de proteger la imparcialidad de las actuaciones". 
En este sentido, la propuesta del Observatorio Jurídico parte de reconocer los atributos de los derechos lingüísticos configurados en la dignidad, la libertad, la igualdad y la identidad en relación con el ejercicio de los derechos de los pueblos indígenas en Venezuela y Ecuador, cuya finalidad es proporcionar un marco para aplicar el enfoque de interculturalidad a las cuestiones lingüísticas, con miras al cumplimiento efectivo de las obligaciones estatales.

En relación a este punto, el Grupo Especial de Expertos sobre las Lenguas en Peligro señala que: "La extinción de una lengua significa la pérdida irrecuperable de saberes únicos, culturales, históricos y ecológicos" (p.2).

Entendiendo que el idioma y las tradicionales orales repercuten de manera considerable en numerosos aspectos que constituyen la esencia de la inclusión y la participación de la población Kichwa y la defensa de sus derechos ante la administración pública y los procesos judiciales, el Observatorio considera oportuno trabajar junto al Centro de Idiomas de la Universidad de Otavalo, al Consultorio Jurídico gratuito de la Universidad de Otavalo, al Instituto Otavaleño de Antropología, el Cabildo Kichwa Otavalo y al grupo de investigación "justicias" de la carrera de Derecho, el "Diccionario Jurídico en lengua Kichwa" y el "Manual para interpretes en procesos judiciales en lengua Kichwa" que permitan la comprensión de vocablos jurídicos para la actuación judicial.

Este proyecto, es un primer paso de los que se estarán desarrollando entre los años 2020 al 2025 y que se sumarán a otras iniciativas que tengan como pilar fundamental la interpretación intercultural en los ámbitos judiciales que armonicen el concepto de plurinacionalidad tan evidentemente anclado en el Cantón de Otavalo.

\section{Conclusiones}

Los derechos lingüísticos de los pueblos indígenas representan un conjunto de normas, nacionales e internacionales que hacen referencia a las lenguas, a su protección y mantenimiento, a su promoción y desarrollo, así como a la promulgación de leyes y la aplicación de políticas lingüísticas y a prescribir un marco claro para su implementación bajo el principio de libertad lingüística de las personas indígenas.

Los derechos lingüísticos son parte integrante de los derechos humanos de los pueblos indígenas de Venezuela, Ecuador y de todo el mundo. Los resultados de la introducción de nuevas regulaciones jurídicas en estos países en aspectos de la política lingüística indígena, muestran que no son suficientes en cuanto a 
la implementación de los derechos otorgados a los pueblos y comunidades indígenas, en la Constitución de 1999 en Venezuela y de 2008 en Ecuador.

La falta de traducción e interpretación de los idiomas ancestrales al castellano de todos los pueblos y nacionalidades de Ecuador y Venezuela conlleva a la imposibilidad del Estado de publicar en sus lenguas las normas constitucionales y legales que conforman el ordenamiento jurídico de sus países.

A pesar de que existen iniciativas que fomentan la enseñanza y aprendizaje de algunos de los idiomas ancestrales, las investigaciones muestran que existe estandarización de un idioma sobre otro, lo que amenaza la transmisión intergeneracional de sus lenguas vernáculas, lo que genera a su vez la extinción progresiva de lenguas ancestrales indígenas.

Aunque se reconoce por una parte, la protección, uso, fomento y promoción de lenguas ancestrales, de derechos colectivos, culturales y sociales con rango constitucional, por la otra, las políticas públicas que se han elaborado en esta última década no responden a la extinción paulatina de las lenguas ancestrales y sus ramificaciones de pueblos y nacionalidades indígenas. Se visibiliza el panorama en el que se encuentran las lenguas indígenas en Ecuador y Venezuela, con lo que se determina que existe responsabilidad estatal por la ausencia de acciones, planes y programas vinculados al estudio, enseñanza y difusión de lenguas ancestrales que garanticen la permanencia de los idiomas ancestrales a nivel local y nacional.

Finalmente, es importante resaltar que las investigaciones que realizan organizaciones internacionales, organizaciones no gubernamentales y universidades, concluyen que existe la necesidad de implementar modelos tecnológicos y pedagógicos en la enseñanza de las lenguas maternas desde las primeras etapas de educación.

\section{Referencias}

ALLAIS, María, (2004). La población indígena de Venezuela según los censos nacionales. Ponencia presentada en el Encuentro nacional de demógrafos y estudiosos de la población, Caracas. Disponible en: $\underline{\text { https://bit.ly/2y42Glb }}$

AYALA, Enrique, (1994). Historia de la Revolución Liberal Ecuatoriana. Disponible en:https://bit.ly/2zNraWF

BAUTISTA, Juan, (1995). Convenio Marco para la Protección de las Minorías Nacionales. Revista de Instituciones Europeas, numero 22. Disponible en: https://bit.ly/2zL9paj 
BELLO, Luis. (2005), Derechos de los pueblos indígenas en nuevo ordenamiento jurídico venezolano, IWGIA, Caracas. Disponible en: https://bit.ly/2Smedtk

CRESPO, Juan. y VILA, David, (2014). Saberes y conocimientos ancestrales, tradicionales y populares (v. 2. 0). Buen Conocer- Flok Society. Documento de política pública 5.2. Quito: IAEN. Disponible en: https://bit.ly/3f7Z7B4

CONEJO, Alberto, (2008). Educación Intercultural Bilingüe en el Ecuador. La propuesta educativa y su proceso. Alteridad, Revista de Educación.Universidad Politécnica Salesiana. Ecuador. Disponible en: https://bit.ly/2KOqGli

CONGRESO NACIONAL DEL ECUADOR, (1998). Constitución política del Ecuador. Disponible en: https://bit.ly/2WiKyCu

CONFEDERACIÓN DE NACIONALIDADES INDÍGENAS DEL ECUADOR, CONAIE, (1988). "Proyecto de Ley de Nacionalidades Indígenas", en Memorias del Segundo Congreso, Quito, Tinkuy. Disponible en: https://bit.ly/2y5LulA

CÓDIGO ORGÁNICODELAFUNCIÓN JUDICIAL. (2009). Asamblea Nacional del Ecuador. Corporación de Estudios y Publicaciones. Disponible en: https://bit.ly/2WcxWwv

CONSEJO NACIONAL PARA LA IGUALDAD DE PUEBLOS Y NACIONALIDADES (2019). Ecuador realiza el lanzamiento oficial del Año Internacional de las Lenguas Indígenas. Disponible en: https://bit.ly/2Tvatpz

CONVENIO 169 DE LA OIT, SOBRE PUEBLOS INDÍGENAS Y TRIBALES, (1989). Organización Internacional del Trabajo, OIT. Disponible en: https://bit.ly/2SovBOI

CONVENCIÓN SOBRE PROTECCIÓN Y PROMOCIÓN DE LA DIVERSIDAD DE LAS EXPRESIONES CULTURALES, (2005). Organización de las Naciones Unidas para la Educación. Disponible en: https://bit.ly/2SmimgS

DECLARACIÓN DE LAS NACIONES UNIDAS SOBRE LOS DERECHOS DE LOS PUEBLOS INDÍGENAS, (2007). Organización de las Naciones Unidas, ONU. Disponible en: https://bit.ly/2VOoTTm

DECLARACIÓN UNIVERSAL DE DERECHOS HUMANOS, (1948). Asamblea General de Naciones Unidas. Disponible en: https://bit.ly/2Skg9Cm

DECLARACIÓN UNIVERSAL DE DERECHOS LINGÜÍSTICOS, (1996). Disponible en: https://bit.ly/3bRy4rX

DECLARACIÓN DE NACIONES UNIDAS SOBRE LOS DERECHOS DE LOS PUEBLOS INDÍGENAS, (2007).Disponible en:https://bit.ly/2WiKyCu

FERNÁNDEZ, Carlos, (2000). Marco jurídico internacional de los derechos lingüísticos. Madrid: Universidad Carlos III de Madrid. Disponible en: https://bit.ly/3bUll2m 
GARCÍA, Fernando, (2009). Trabajo Infantil Indígena. Facultad Latinoamericana de Ciencias Sociales FLACSO, sede Ecuador. Disponible en: https://bit.ly/2ydriy6

GONZÁLEZ, N, (2010). Sistemas jurídicos contemporáneos. México: Nostra Ediciones. Disponible en: https://bit.ly/3kqadnp

GUÍA PRÁCTICA PARA LA APLICACIÓN DE DERECHOS LINGÜÍSTICOS DE LAS MINORÍAS LINGÜÍSTICAS, (2017). Relator/a Especial de las Naciones Unidas sobre cuestiones de las minorías c/o Oficina del Alto Comisionado para los Derechos Humano. Ginebra. Disponible en:https://bit.ly/2YjPUjq

GRZECH, Karolina, (2017). ¿Es necesario elegir entre la estandarización de las lenguas minoritarias y la vitalidad de sus variedades? Estudio de caso del kichwa de Alto Napo. Las lenguas amerindias en Iberoamérica: retos para el siglo XXI. ONOMÁZEIN - N. ${ }^{\circ}$ especial. Disponible en: https://bit.ly/3aUnYVQ

GRUPO ESPECIAL DE EXPERTOS SOBRE LAS LENGUAS EN PELIGRO, (2003). Vitalidad y peligro de desaparición de las lenguas. UNESCO. Disponible en: https://bit. ly/2HsYu9g

INSTITUTO DE IDIOMAS, CIENCIAS Y SABERES ANCESTRALES, (2016). Informe de rendición de cuentas 2016: En cumplimiento a la Ley Orgánica de Participación Ciudadana (LOPC) y Ley Orgánica del Consejo de Participación Ciudadana y Control Social(LOCPCCS). Disponible en: https://bit.ly/35leMsh

KRZYWICKA, Katarzyna, (2011). Situación Jurídica de los Pueblos Indígenas en Venezuela. Dilemas de Representación y Participación. Revista del CESLA, núm. 14, Varsovia, Polonia. Disponible en: https://bit.ly/35gw3Da

LEY ORGÁNICA DE CULTURA, (2016). Asamblea Nacional del Ecuador. Disponible en: https://bit.ly/2ySS5zQ

LEY ORGÁNICA DE PUEBLOS Y COMUNIDADES INDÍGENAS, (2005). Gaceta Oficial, No. 38344, Caracas, 27 de diciembre. Disponible en: https://bit.ly/3eZT69P

LEY ORGÁNICA DE EDUCACIÓN SUPERIOR, (2010). Registro Oficial Suplemento 298. Disponible en: https://bit.ly/2yT2AmC

MEJEANt, Lucía, (2001). Culturas y lenguas indígenas en el Ecuador. Revista Yachakuna. Disponible en: https://bit.ly/2WfBuhl

MINISTERIO DE EDUCACIÓN, (2017). Ley Orgánica de Educación Intercultural. Disponible en: https://bit.ly/2VQRUOh

MINISTERIO DE EDUCACIÓN, (s.f.). Dirección Nacional de Educación Intercultural Bilingüe. Disponible en 20 de abril del 2020: https://bit.ly/3d4zcsa 
OLIVEROS, Yuri. (2017). Derechos humanos y derechos lingüísticos indígenas de Colombia. Derecho y Realidad, 15(29). UPTC. Colombia. Disponible: https://bit. ly/3d2Qgii

PACTO INTERNACIONAL DE DERECHOS CIVILES Y POLÍTICOS, (1966). Asamblea General de Naciones Unidas. Oficina del Alto Comisionado de Derechos Humanos de Naciones Unidas. Disponible en: https://bit.ly/2Wg7UZI

PEÑALOSA, J. (2016) , Desarrollo de un sistema móvil para el aprendizaje inicial del lenguaje ancestral Shuar. Quito: Universidad Tecnológica Israel. Disponible en: https://bit.ly/3jlPVu6

PÉREZ, Luis, (2004). Los wayuu: tiempos, espacios y circunstancias. Espacio abierto, 13(4), 607-630. Redalyc Venezuela. Disponible en: https://bit.ly/2VOWpc7

PROYECTO NACIONAL SIMÓN BOLÍVAR, (2007). Desarrollo Económico y Social de la Nación 2007-2013, Caracas. Disponible en: https://bit.ly/3bPrPoo

REGNAULT, Blas, (2005). La población indígena y afrodescendiente de Venezuela y el aporte del censo indígena en el estudio de la asistencia escolar. Ponencia presentada en el encuentro internacional de CEPAL, Santiago, Chile.Disponible en: https://bit.ly/2VQEhic

SALAZAR. D. (2015) ,"Modelo Funcional de Enseñanza de Lengua Andwa para Maestros". Quito: Pontificia Universidad Católica del Ecuador. Disponible en: https://bit.ly/3koesQi

SKUTNABB-KANGAS, TOVE. \& PHILLIPSON, Robert, (1994). Linguistic Human Rights, Past and Present. New York: Mouton de Gruyter. Disponible en: https://bit.ly/2yeKxqT

VENEZUELA, INSTITUTO NACIONAL DE ESTADÍSTICA, (2001). XIII Censo General de Población y Vivienda. Instituto Nacional de Estadística. Disponible en: https://bit. ly/3d5uL0z

VENEZUELA, INSTITUTO NACIONAL DE ESTADÍSTICA, (2001). Ficha técnica del Censo de Comunidades Indígenas. Instituto Nacional de Estadística. Disponible en: https://bit.ly/2KOWnuy

UNIVERSIDAD DE OTAVALO, (2019). Centro de Idiomas. Disponible en: https://bit. ly/2VOfKdF 